This item was submitted to Loughborough's Research Repository by the author.

Items in Figshare are protected by copyright, with all rights reserved, unless otherwise indicated.

\title{
Editorial for the Special Issue on "Securing future of heritage by reducing risks and building resilience"
}

PLEASE CITE THE PUBLISHED VERSION

https://doi.org/10.1108/DPM-02-2020-397

PUBLISHER

Emerald

VERSION

AM (Accepted Manuscript)

PUBLISHER STATEMENT

This paper was accepted for publication in the journal Disaster Prevention and Management and the definitive published version is available at https://doi.org/10.1108/DPM-02-2020-397

LICENCE

CC BY-NC-ND 4.0

\section{REPOSITORY RECORD}

Chmutina, Ksenia, R Jigyasu, and T Okubo. 2019. "Editorial for the Special Issue on "securing Future of Heritage by Reducing Risks and Building Resilience"”'. figshare. https://hdl.handle.net/2134/9637967.v1. 


\section{Editorial for the Special Issue on "Securing future of heritage by reducing risks and building resilience"}

Ksenia Chmutina ${ }^{1 *}$, Rohit Jigyasu ${ }^{2}$ and Takeyuki Okubo ${ }^{3}$

$1^{*}$ School of Architecture, Building and Civil Engineering, Loughborough University, UK; Corresponding author: k.chmutina@lboro.ac.uk

2 International Centre for the Study of Preservation and Restoration of Cultural Property (ICCROM), Sharjah, UAE

${ }^{3}$ Institute of Disaster Mitigation for Urban Cultural Heritage, Ritsumeikan University, Kyoto, Japan

\section{Introduction}

Cultural heritage is diverse. It is represented by a broad array of places such as monuments, archaeological sites, vernacular housing, historic settlements, cultural landscapes, industrial sites as well as those that are associated with painful past such as wars or accidents.

Museums, libraries and archives (and the collections they hold) are also important components of heritage, as are intangibles such as knowledge, beliefs and value systems that have strong impact on people's way of life.

However, this vast range of heritage is also increasingly exposed to various natural and human induced hazards such as earthquakes, floods, fires, hurricanes, landslides, terrorism and armed conflicts. In the recent years, disasters have caused extensive damage to cultural heritage. These include recent fires in Notre Dame Cathedral in Paris on $15^{\text {th }}$ April 2019 and in the National Museum of Brazil on 3rd September 2018 that significantly damaged the historic built fabric as well as collections of great heritage value. Huge loss of cultural heritage due to devastating earthquakes in Central Mexico in 2017, central Italy and Myanmar in 2016, and Nepal in 2015 further brought forward the need to undertake immediate measures to mitigate such a massive loss to heritage due to disasters. Moreover, recent conflicts have also caused enormous damage to cultural heritage in places such as Syria and Iraq.

Climate change has also been exacerbating the vulnerability of cultural heritage. Since 1988, at least 76 per cent of all disasters have been induced by hydrological and meteorological hazards; only in 2018 there had been 10 climate-induced disasters, each causing a damage of over US\$1 billion (Christian Aid, 2018).

The Intergovernmental Panel on Climate Change (IPCC) special report (2012) on managing the risks of extreme weather events to advance climate change adaptation confirms the 
likelihood of their increased frequency and intensity in the future, suggesting that the number as well as the scale of weather-related hazards may thereby increase risks to cultural heritage. For instance, abnormally high temperatures, rising water levels and changing levels of moisture in some regions constitute underlying risk factors that can affect heritage.

Besides loss to the material fabric, disasters also affect intangible heritage including traditional knowledge, practices, skills and crafts that ensure continuity of living cultural heritage as well as means for its maintenance and conservation. However to date the focus has largely been on tangible heritage in isolation, without taking into account a broader context that includes intangible dimension and the social, economic, geographical and institutional dimensions of the region, in which heritage is situated.

Heritage not only gives identity to community, but also makes direct and significant contribution to sustainable development across its economic, social and environmental dimensions. The loss of tangible and intangible cultural heritage can affect cultural and social values and their role in sustainable development (Boccardi and Duvelle, 2013; UNESCO, 2017). A recent agreement between the UN and World Bank explicitly states that cultural heritage and sustainable tourism have become key economic drivers for poverty reduction and job creation, especially for women and youth (World Bank, 2017). Culture is directly addressed in Sustainable Development Goal (SDG) 11 - Make cities and human settlements inclusive, safe, resilient and sustainable, and SDG 13 - Take urgent action to combat climate change and its impacts.

It has also been recognised as a key dimension of disaster risk reduction and the need to protect and draw upon various benefits of heritage as an asset for resilience (UN, 2015; Hellgate et al. 2016). Traditional knowledge systems embedded in cultural heritage can play a significant role in disaster prevention and mitigation and provide the foundation for coping capacities. Lessons learnt from the past and indigenous understanding of local hazards, climate, natural resources and geography is embedded in cultural heritage and can be used in restoration work as well as in new construction. This emphasises the important role of $\mathrm{CH}$ in development that is both resilient and sustainable (Ravankhah et al. 2016, Okubo, 2018).

A key factor indicating the need to increase the resilience of cultural heritage is the particular fragility of their historic fabric and higher vulnerability (due to ageing materials, limited critical infrastructure for emergency and urban density) to natural hazards and human-induced threats. The increasing pressures on cultural heritage especially in urban areas, due to the geo-physical environment, carrying capacity and socio-economic developments are likely to reach a critical point in the near future and require urgent action. To date however little academic research has been undertaken that addressed the specific 
disaster risks confronting cultural heritage and the effectiveness of various initiatives undertaken to manage disaster risks (Jigyasu, 2016).

The special issue has endeavoured to present a collection that contributes to addressing this research gap in the area of disaster risk management of cultural heritage and presents a wide range of publications that contribute to deepening our knowledge of diagnosis, treatment and a better understanding of the historical, social and technological contexts of heritage as well as improved risk management and inputs to conservation and adaptation policies for cultural heritage, and to promoting improved practices for the guardians of cultural assets in historic urban areas.

\section{What we have achieved}

The global attention to challenges faced by cultural heritage in the context of disaster risk first came to light when floods in Florence in 1966 caused extensive damage to cultural heritage, destroying millions of masterpieces of art and rare books. International Centre for the Study of the Preservation and Restoration of Cultural Property (ICCROM) launched a massive operation to salvage heritage (Hamburg, 2018). Another landmark event was 1995 Kobe earthquake, when wooden heritage was lost due to post earthquake fires (Toki et al., 2004). In spite of these large events, the fields of cultural heritage conservation and disaster risk management had virtually no connection, and there was no comprehensive effort to reduce disaster risks to cultural heritage until the World Conference on Disaster Risk Reduction in 2005 to commemorate the $10^{\text {th }}$ anniversary of Kobe earthquake.

During this conference, a thematic meeting on heritage and disasters was organised jointly by UNESCO, ICCROM, ICOMOS (International Council on Monuments and Sites) and Ritsumeikan University, Kyoto. This was probably the first time that issue of cultural heritage was discussed in a conference on disaster risk management. In the following year, first ever training course on the subject was initiated. The course, now (in 2019) in the $14^{\text {th }}$ year of its inception, has immensely contributed towards developing the capacity of professionals from both disaster risk management and cultural heritage conservation to manage disaster risks to cultural heritage through an integrated approach aimed at mitigating, preparing, rescuing and recovering cultural heritage in times of a disaster. Based on the practical experience of Japan, various lectures, exercises and field visits are conducted during the three weeks long course, guiding the participants through the development of their own case studies that comprise cultural heritage sites and/or museums from their own country. The course has been successfully creating a fraternity of cultural heritage disaster risk managers from over 50 countries. Bosher et al. (in this issue) provide an overview of the 80 case studies prepared by the ITC participants from 2006-2016; the course Resource Persons and Alumni (Kim (see the paper by Ishida et al.), Minguez Garcia, Marchezini) have also contributed to this Special Issue sharing their experiences, best practices and challenges. 
Another capacity building initiative focuses on embedding cultural heritage in humanitarian response during emergency situations: the First Aid to Cultural Heritage ${ }^{1}$ (FAC) course has been organised by ICCROM since 2010. Through targeted training and sharing of knowledge, FAC enables communities, cultural heritage professionals, humanitarians and emergency responders to work together and reduce risks of damage and destruction.

Several countries, such as Myanmar and Bhutan (supported by international organisations such as World Bank and UNESCO) have taken initiatives towards preparing disaster risk management plans tailored to the characteristics of their cultural heritage sites and addressing the constraints and opportunities offered by them. Many other initiatives lead by international organisations such as \#unite4heritage by UNESCO, \#culturecannnotwait by ICCROM, and 'ICORP on the Road' by ICOMOS, have brought out success and failures in disaster risk management of cultural heritage.

Meanwhile, Sendai Framework on Disaster Risk Reduction adopted in 2015 for the first time explicitly included reference to cultural heritage (Target C-6), providing boost to the ongoing efforts in this area. This key international policy framework now clearly recognises culture as a key dimension of disaster risk reduction and the need to protect and draw on heritage as an asset for resilience through a number of important references. Along with progress on policy and advocacy front, several knowledge resources have also been produced. UNESCO developed key resource manual on managing disaster risks to cultural heritage in $2010^{2}$, along with manuals for managing natural ${ }^{3}$ and cultural ${ }^{4}$ world heritage sites respectively. The manuals are aimed at guiding site managers to develop and implement a comprehensive disaster risk management plan following a systematic process based on an integrated framework.

The challenge however is to implement these global initiatives; this requires considerable building of capacities at international, national and local/community levels and the setting up of the necessary institutional mechanisms, complemented by data collection and monitoring. In spite of noteworthy advances in this area in terms of research, training and advocacy, development of international policies, tools and knowledge resources such as manuals in the field, critical challenges remain as outlined in the next section.

\section{What we need to achieve}

One of the critical challenge is that all these well-intentioned words are not turning into effective actions and there is much less success in actually achieving disaster risk reduction of cultural heritage. In many World Heritage Sites, the managers have either not undertaken

\footnotetext{
${ }^{1}$ For more information, see https://www.iccrom.org/section/disaster-resilient-heritage/first-aid-culturalheritage-times-crisis-fac

${ }^{2}$ See https://whc.unesco.org/en/managing-disaster-risks/

${ }^{3}$ See https://whc.unesco.org/en/managing-natural-world-heritage/

${ }^{4}$ See https://whc.unesco.org/en/managing-cultural-world-heritage/
} 
systematic assessment of disaster risks or any action to reduce these risks at their respective sites. Even the manuals and other learning resources have found limited applicability as the provided guidance does not connect well with the day to day maintenance and monitoring activities of those who are managing the site. This also means that rather than basing our success outcomes on the development of stand-alone comprehensive disaster risk management plans for heritage sites, we should assess their implementation as an integral part of the management system for the site where disaster risk management gets mainstreamed into effective management actions that help in reducing risks through maintenance and monitoring. Most importantly, concerted efforts at the national level are required to connect heritage and disaster risk management sides through interdepartmental coordination and support of various national and international actors.

Some successful examples of turning words to action of course exist. Minguez Garcia (this issue) presents a practitioners' perspective on how international collaboration can lead to knowledge exchange between academics, non-governmental organisations, donors, local governments and communities, and help finding solutions on the ground. Japan is well known for their comprehensive policy on disaster risk management and their extensive experience of implementing various top-down and bottom-up approaches that help enhancing resilience of cultural heritage at a community level; some of such approaches have been contextually adjusted to be replicated in Bhutan.

Whilst it is acknowledged that the contexts are different - and it is important to devise solutions that are sensitive to local context. These may be high-tech or simple but most importantly, these should be locally appropriate. Therefore there are no 'silver bullets' for good solutions. All that is needed is to grasp the ideas, tailor and creatively apply them to local conditions. What's interesting however is that, whilst the solutions require tailoring, the challenges posed by disasters for research as well as practice are shared by many cultural heritage sites around the world, as demonstrated by Bosher et al. (this issue). It is thus important to understand what strategies are being adopted to mitigate disaster risks and which of these strategies can be transferred (albeit adapted) into different contexts as they are not technology-heavy but instead rely on changes in governance and behaviour, thus addressing the root causes of the heritage vulnerability. Understanding these similarities will help mainstreaming disaster risk management into daily practices and encourage collaboration and cooperation.

Another challenge lies in the way the risks are assessed. Mitigating risks to cultural heritage necessitate comprehensive risk assessment that takes into consideration multiple hazards and multiple - social and physical - vulnerabilities that can sometimes be intertwined. Physical vulnerabilities may have accrued due to poor construction, lack of maintenance or due to previous interventions, following past disasters. These actions are not always malicious - and are not always known; yet they must be considered. Putrino and D'Ayala (this issue), using the example of a historic town of Norcia (Italy), explore the dynamic 
evolution of the damages that were caused by the earthquakes in 2016 and 2017, and propose risk assessment methodology to explore such evolution. Whilst the historic masonry buildings withstood the impact of an earthquake in August 2016, they were severely damaged and in some cases destroyed in the next earthquake few months later. It is thus important to understand the efficacy of historic and more recent structural interventions to understand what structural measures should be used (and how) in reconstruction process.

Although it is important to consider physical aspects of vulnerability, the social, economic, institutional and attitudinal dimensions of vulnerability should not be overlooked, as these often point towards underlying root causes linked to issues related to inherent power relations within community(ies), transparency and accountability in governance etc. that need to be addressed for long term vulnerability and risk reduction, or else we run the risk of recreating vulnerabilities in spite of investing time and resources in mitigation measures. The connections between physical and social vulnerabilities have already been to some extent established through works of scholars such as Cutter (1996; Cutter et al., 2003; Cutter and Morath, 2013) but these need to be further developed to reflect the reality especially in the context of cultural heritage.

Vulnerability and capacity assessments (VCA) have also become popular in disaster risk management of cultural heritage; if carried out appropriately, taking local context into account, they can play an essential role in enhancing local people's confidence making their opinions heard and taken into account. As pointed out earlier, through assessment of local capacity, heritage is not just seen as vulnerable but as a source of resilience through local knowledge and skills that are part of the intangible heritage. Wu and $\mathrm{Hou}$ (this issue) describe how intangible heritage - i.e. traditional knowledge and skills - of the people living in Guchengping were used in the reconstruction after the 2013 Lushan earthquake (Sichuan, China). Here the villagers were involved in deciding the spatial layout and designs of the houses, and were invited to share their practices with the reconstruction team comprising of professionals. Through a co-design process, the professionals enabled the local residents to better understand the strategic plan coming from the government and provided opportunity to the local community to customise their action according to their needs. This process also enabled further enhancement of the traditional skills by engaging with up-todate techniques, which further led to an increased sense of ownership and trust.

However we should be careful in solely relying on such assessments when discussing cultural heritage and its role in increasing communities' resilience. After all, VCA is merely a management tool that is based on the pre-defined concepts (whether they make sense locally or not) and quantitative and/or demographic indicators that help ticking the box. People and their heritage cannot always be understood through standard criteria and methodologies designed by outsiders. An interpretation of an outsider would always reflect 
their own knowledge, assumptions, and values, thus 'creating false 'stories' that fit her or his expectations' (Bhatt, 1998, p. 71).

Assessing and strengthening capacities should therefore be considered as an insider-driven process. An effective VCA should help emphasise, among other things, the process through which people realise by themselves the extent, strength and diversity of their individual and collective capacities that are embedded in heritage - and how these can be maximised when facing hazards. This capacities are particularly important to understand in reconstruction of cultural heritage, as emphasised by Ishida et al. (this issue); the authors however point out that the link to community is also critical when deciding what should be restored and how. Here a disaster is seen as an opportunity that allows re-establishing the values of heritage, and to re-evaluate its purposes for and the role in community.

Moreover in the context of disaster risk management of cultural heritage (and broader disaster risk management), the focus is still largely on vulnerabilities or the lack of capacity (i.e. what people cannot do as opposed to what they can do) - and this patronises the work of many organisations and community efforts that are not taken into account.

We also need to remember that capacity and vulnerability are not on the same spectrum: building capacity does not reduce vulnerability, as vulnerability is ingrained in political and social systems. Realistically, disaster risk management and cultural heritage practitioners and researchers can rarely address the societal root causes of vulnerability. This however does not mean that vulnerabilities should be neglected when developing capacity; both should be addressed in tandem.

Capacities differ: often those who are seen as the most marginalised and vulnerable can make up for their lack of access to economic and political resources by relying upon strong social and human resources - and these are often founded in heritage. Thus it is important to understand that capacities are people- and context- specific. The recognition of diverse capacities from diverse range of communities gives primary importance to utilising local resources and emphasising the overarching contribution of local communities in facing natural hazards. Local capacity however should not be romanticised: whilst traditional knowledge can help dealing with frequent flooding, it is not enough to build a large dike to prevent a long-term flooding. Moreover in some cases, traditional knowledge and practices can even enhance vulnerability: deeply-rooted discriminatory socio-cultural values and traditions exclude some community groups from participation. We also should not forget about external and scientific knowledge; this knowledge can also help with dealing with future events, such as climate change, the full impacts of which are still not clearly understood - but already experienced. It is thus important to consider how local capacities can be intertwined with external support in an integrated manner (Gaillard et al., 2019). 
We also need to focus on mainstreaming cultural heritage into broader disaster risk management processes. Currently, we still treat cultural heritage as a siloed area - but it is in the fabric of our lives, through its tangible and intangible representations, and is thus having an impact on how we prepare and respond to disasters. Losses and damages to cultural heritage thus need to be included into post-disaster assessments as well as prevention and mitigation systems, which would require updating of existing tools and methodologies as well as a better collaboration between heritage conservation and disaster risk management sectors. Marchezini et al. (this issue) present an example of successful dialogue between heritage sector, civil defence agencies and local communities that led to establishing an early warning system that provides information about heritage at risk in the town of São Luiz do Paraitinga. This case study shows how both scientific data and participatory mapping can be incorporated and shared to enhance resilience of cultural heritage - and communities that the heritage belongs to.

We should also explore more how knowledge developed in related areas - such as crime can be shared and used for disaster risk management of cultural heritage. Thomas et la. (this issue) explore how the data on crime heritage can help establishing what damage can be done - and how it can be prevented. Very little data is however available at the moment - and it is important to engage the community. Whilst crime is not often discussed in disaster risk management, it is a salient threat and should be considered when developing risk management strategies.

\section{Concluding remarks}

This special issue has been conceived through numerous discussions and practical work, through frustrations and successes - and as this editorial demonstrated, we've achieved a lot but we have still a long way to go.

Cultural heritage cannot be seen in an exclusive manner devoid of its larger social and economic context. After all, heritage is an inherent part of human identity that is closely intertwined in day-to-day lives of people. Thus cultural heritage needs to be embedded in disaster risk management (and not treated as a specific area that may or may not be focused upon if disaster strikes) in order to ensure its mainstreaming in a true sense. Cultural heritage is not static in time; rather is continuously evolving in response to changes including those induced by disasters. Therefore disasters provide an opportunity to reevaluate and re-configure heritage values while reducing vulnerability by building back better and also enhancing the quality of life of the people.

The failure of many attempts to increase the resilience of cultural heritage is generally blamed on the lack of data related to hazards, vulnerability and exposure before disasters and on damage and losses after disasters. But we must ask ourselves - do we always need all data that the guidelines are telling us to rely on? Should we invest more to understand what 
data is required and why - and who will be using it and for what purpose? Data in itself cannot reduce disaster risks. Should we just be more systematic in the way we collect data and work on developing a closer communication between heritage agencies and those from other sectors?

We mostly still think and work in silos: cultural heritage is considered as a separate sector as are disaster risk management, urban planning, climate change, sustainable development, and many other areas concerned with socio-political issues. But such a compartmentalised approach increases duplication of efforts and decreases efficiency. Many of the solutions that are proposed in disaster risk management for new urban developments can be appropriate for climate change adaptation measures for cultural heritage; many tools can be shared and applied holistically, thus mainstreaming cultural heritage in sustainable development efforts (Chmutina et al., 2017).

It is also important to put more efforts in promoting and implementing multi-stakeholder engagement - but we should not forget the political dimension of heritage, the value of which is often decided by the stakeholders with more power. Heritage is a construct and its definition and recognition is linked to the individuals or communities who define and value it. That is why, whilst the role of the community is an important part of any disaster risk management efforts (and this has been highlighted in all the papers in this Special Issue), very often the idea of communities in many of disaster risk management approaches is rather simplified. Often we do not take into account cross sections of communities; are we really engaging all? Who's heritage are we protecting? Marginalisation is an issue in cultural heritage, and by claiming to engage with the 'community' we are hiding a lot of issues that lie at the roots of vulnerability. Communities are never homogenous: the information asymmetries and unequal distributions do not only exist between a community and other political actors, but also within the community (Pelling, 1998). Therefore the idea of heritage is closely linked to the inherent power relations in the community. It would be pertinent to ask whether vulnerability and risk reduction of one aspect of heritage is not at the expense of heritage belonging to the weak and marginalised. The issues of power, donors (who bring what for what?) and leadership also play a role in deciding whose heritage is protected by whom and how.

Inclusivity is extremely hard to ensure, particularly in those societies without a history of public involvement in decision-making or in deeply divided communities (e.g. migrant communities, slums). As noted earlier, political neglect and social discrimination are often evident when capacities of certain marginalised groups are ignored. Therefore practical shift towards mainstreaming disaster risk management of cultural heritage requires trade-offs at multiple levels, between and among various sectors and between and among various sections of the community and their representatives. 
This also means that professionals from different disciplines need to recognise each other's issues and vocabularies. Although we attempt to provide universally accepted definitions of terms related to disaster risk management of cultural heritage, actually it is not very useful; all the terms are malleable but can be useful because we can then connect people to work in a cross-disciplinary and collaborative manner. This special issue written by disaster risk management professionals from diverse disciplinary background is the testament to the need of looking at all the interpretations.

Another important issue is that most of the efforts towards reducing disaster risks have been directed at the tangible manifestations of heritage at the expense of the intangible aspects. However tangible and intangible dimensions are intertwined and therefore disaster risk management of intangible heritage would ensure that sustainability of tangible heritage. This would also necessitate efforts towards addressing root causes of social and economic vulnerability of those communities who are true bearers of heritage. How do we focus on intangible whereas all we produce is tangible? This - and many other questions are yet to be answered, and we hope that this Special Issue will inspire seeking - and sharing some of these answers.

To conclude, though there are still many challenges to meet and hurdles to cross for making cultural heritage disaster safe, one can safely say that appreciable strides have been made in practical and theoretical achievements at national, local and site levels through untiring efforts of researchers and practitioners from cultural heritage and disaster risk management sides, as eloquently shown by the articles included in this Special Issue. These good practices should serve as case studies that need to be appreciated and adapted to the local contexts for making our cultural heritage safe and resilient.

Acknowledgements: Daiwa Foundation Small Grant (Award reference number 14/15-35), British Academy Fellowship (Award reference number VF1/102103), Loughborough University's CALIBRE Seed Funding (2017), Ritsumeikan Univeristy and the International Training Course on Disaster Risk Management for Cultural Heritage, ICCROM, and all the authors and reviewers that made this Special Issue a reality.

\section{References}

Bhatt, M.R. (1998), “Can vulnerability be understood?”, in Twigg, J. and Bhatt, M.R. (Eds.), Understanding vulnerability: South Asian perspectives, Intermediate Technology

Publications, London, pp. 68-77.

Boccardi, G. and Duvelle, C. (2013), "Cultural Heritage and Sustainable Development: A Rationale for Engagement", available at: http://www.unesco.org/new/fileadmin/MULTIMEDIA/HO/CLT/images/HeritageENG.pdf (accessed 13 August 2019). 
Chmutina, K., Jigyasu, R. and Bosher, L. (2017), "Integrating DRR including CCA into the delivery and management of the built environment", in Kelman, I., Mercer, J. and Gaillard, J.C. (Eds.), Routledge Disaster Risk Reduction and Climate Change Adaptation Handbook. Routledge, Ch. 25

Christian Aid (2018), "Counting the costs: a year of climate breakdown", available at: https://reliefweb.int/sites/reliefweb.int/files/resources/Counting the Cost-pdf.pdf (accessed 13 August 2019).

Cutter, S. (1996), "Vulnerability to environmental hazards", Progress in Human Geography, Vol.20, pp. 529-539.

Cutter, S. and Morath, D. (2013), "The Evolution of Social Vulnerability Index", in Birkmann, J. (Ed.), Measuring vulnerability to natural hazards. $2^{\text {nd }}$ ed. United Nations University Press, Bonn, Germany, pp. 304-21.

Cutter, S.L., Carolina, S., Boruff, B.J., Shirley, W.L. (2003), "Social vulnerability to environmental hazards", Social Science Quarterly, Vol. 84, pp. 242-61.

Gaillard, J.C., Cadag, J.R. and Rampengan, M.M.F. (2019), "People's capacities in facing hazards and disasters: an overview", Natural Hazards, Vol. 95, pp. 863-76.

Hamburg, D.A. (2018), "The Florence Floods of Today", in Conway, P. and Conway, M.O. (Eds.), Flood in Florence, 1966: A Fifty-year Retrospective, Michigan Publishing, University of Michigan Library, Ann Arbor.

IPCC (2012), "Managing the Risks of Extreme Events and Disasters to Advance Climate Change Adaptation. A Special Report of Working Groups I and II of the Intergovernmental Panel on Climate Change", Cambridge University Press, Cambridge, UK, and New York, NY, USA.

Jigyasu, R. (2016), "Reducing Disaster Risks to Urban Cultural Heritage: Global Challenges and Opportunities", Journal of Heritage Management, Vol. 1, Iss.1, pp. 59-67.

Okubo, T. (2018), "Traditional Knowledge of Disaster Resilient Designs in World Cultural Heritage, Japan for Cultural Conservation and Disaster Mitigation", Abitare La Terra, No. 46 \& 47, pp. 32-33.

Pelling, M. (1998), "Urban flooding in Guyana", Journal of International Development, Vol. 10, pp. 469-86.

Ravankhah, M., Chmutina, K., Schmidt, M. and Bosher, L. (2017), "Integration of Cultural Heritage into Disaster Risk Management: Challenge or Opportunity for Increased Disaster Resilience", in Albert, M.-T., Bandarin, F. and Pereira Roders, A. (Eds.) Going Beyond Perceptions of Sustainability, Heritage Studies No. 2. 
Toki, K., Okubo, T. and Izuno, K. (2004), "Protection of cultural heritages from postearthquake fire", in Proceedings of the 13th World Conference on Earthquake Engineering, Vancouver, B.C., Canada, August 1-6, Paper No. 2781.

UNESCO (2017), "World Heritage Convention and Sustainable Development", WHC/17/41.COM/5C, available at: https://whc.unesco.org/archive/2017/whc17-41com-5Cen.pdf (accessed 13 August 2019).

World Bank (2017), "UNESCO and World Bank Collaborate on Culture, Urban Development, and Resilience", Press Release No: 298, available at:

https://www.worldbank.org/en/news/press-release/2017/07/13/unesco-and-world-bankcollaborate-on-culture-urban-development-and-resilience (accessed 13 August 2019). 